\title{
An investigation of concrete stress-strain behavior by the image analysis method
}

\author{
Mahfuz Pekgöz (Main Author and Corresponding Author) \\ Department of Civil Engineering, Karabük University \\ 78000, Karabük (Turkey) \\ mahfuzpekgoz@karabuk.edu.tr \\ https://orcid.org/0000-0002-9529-8537

\section{Osman Günaydın} \\ Department of Civil Engineering, Adıyaman University \\ 02030, Adıyaman (Turkey) \\ gunaydin@adiyaman.edu.tr \\ https://orcid.org/0000-0001-7559-5684
}

\section{Kadir Güçlüer}

Vocational Schools of Technical Science, Department of Construction, Adıyaman University

Adıyaman 02030 (Turkey)

kgucluer@adiyaman.edu.tr

https://orcid.org/0000-0001-7617-198X

Manuscript Code: 25161

Date of Acceptance/Reception: 07.04.2021/08.12.2020

DOI: $10.7764 /$ RDLC.20.2.308

\begin{abstract}
Concrete is a composite load-bearing building material. The deformation behavior of load-bearing materials under load is vital for the building system. Investigation of these brittle and quasi-brittle behavior patterns at various load levels provides an advantage in the evaluation of mechanical properties. In this study, the deformations occurring within the concrete samples in different stress-strain regions were investigated using an image analysis technique. The experimental samples experienced elastic-limit loading for two hours to clearly monitor the deformations at elastic, plastic, and breaking points. For the microstructure studies, the samples were prepared with epoxy for image analysis. Thin-sections were taken from each series of epoxy-impregnated concrete test samples, examined under a microscope, and photographed. Deformation studies on the digital photographs were carried out by the image analysis method. The results show that crack formation and crack types change because of increased stress and deformations. Crack formations within the concrete are parallel to the loading direction and occurred mainly in the aggregate-cementpaste interface. At $85 \%$ of the ultimate stress, crack length was measured as $0.665-29.505 \mathrm{~mm}$ and crack width $0.180-4.128 \mathrm{~mm}$, while the crack length was $0.305-32.688 \mathrm{~mm}$ and crack width were $0.106-2.906 \mathrm{~mm}$ at fracture stress.
\end{abstract}

Keywords: concrete, stress-strain behavior, microstructure, image analysis.

\section{Introduction}

With the increasing use and popularity of concrete, researchers are analyzing this material in more detail to determine its true behavior. Concrete structures suffer significant damage under static and dynamic loads. Damage to concrete is often associated with crack formation, which structurally compromises its functionality, and deterioration in the longterm durability of the material (Kong et al., 2019; Lang et al., 2019). The loss of strength in concrete begins with the emergence and spread of microcracks. Accordingly, numerous studies have highlighted the important effect of microcracks on the bearing properties of concrete (Castro C Sánchez, 2008; Upadhyaya \& Sridhara, 2012).

The aggregate-cement-paste interface significantly affects the short-term behavior of concrete under pressure load. When a load is applied to either aggregate or hydrated cement paste, both stress-strain curves are almost similar to the behavior of a linear elastic body. However, the stress-strain curve of concrete is not linear (Mehta, 2006). The nonlinear behavior of concrete reveals the presence of an aggregate-cement-paste interface and shows microcracking on this contact surface even at the smallest load. These microcracks in the aggregate-cement-paste interface can be considered a defect of the concrete material. Research has revealed that microcracks exist on the contact surface between the aggregate and the cement paste, even before any load is applied (Bentz, 2006; Golewski, 2018; Mehta \& Monteiro, Profant et al., 2019; Shen et al., 2016). Since the cracking process of concrete is difficult to visually examine, detection and analysis on a microcrack scale is still a challenge today (Bazant \& Hubler, 2014; Alembagheri \& Ghaemian, 2013; Xue et al., 2018; Yang \& Chen, 2019; Mahfuz \& Ilker, 2021). Examining the deformations and properties of concrete 
materials with up-to-date technology with various methodologies can yield significant results (Erdem et al., 2018; Li, 2014).

In typical aggregate concretes, crack progression with increasing compressive stress is shown in Figure 1. Research has shown that cracks in the aggregate-cement-paste interface area occur at $40 \%$ of the maximum, or ultimate, stress. At $60 \%$, the cracks suddenly and significantly increase, and at $80 \%$, a continuous microcrack network is evident (Mindess \& Young, 1986). Likewise, data in the literature has demonstrated that cracks in concrete spread steadily in the cement paste at $80 \%$ of the maximum stress (Meyers, 1968; Santiago \& Hilsdorf, 1973). Johnston (1970) states that the cracks in concrete spread steadily in the cement paste at $60 \%$ of the maximum stress and in the cement dough at $80 \%$. Bache C Christensen (1965) determined that cracks in the concrete spread at $90 \%$ of the maximum stress into the cement paste. Supporting this information, Tanigawa \&Yamadaka (1978) found that the cracks in the concrete spread into the cement paste in the direction parallel to the compressive loading also at $90 \%$ of the maximum stress. In other experimental studies, cracks in concrete spread at $70 \%$ of the maximum stress into the cement paste (Jones \& Gatfield, 1955; Zaitsev \& Wittmann, 1973). In another study carried out for the same purpose, cracks in the concrete are not observed at $50 \%$ of the maximum stress; at $70 \%$, cracks are observed in the cement paste; and at $90 \%$, it is transformed into a continuous microcrack web and spread into the cement paste (Malek et al., 2017). However, Lilliu \& van Mier (2007) noted that cracks in the concrete are not apparent at 35\% of the maximum stress, appear in the aggregatecement-paste interface at $51 \%$, and spread into the cement paste at $81 \%$. Zhang et al. (2007) found that the cracks in the concrete are moving into the cement paste at $67-71 \%$ of the maximum stress.

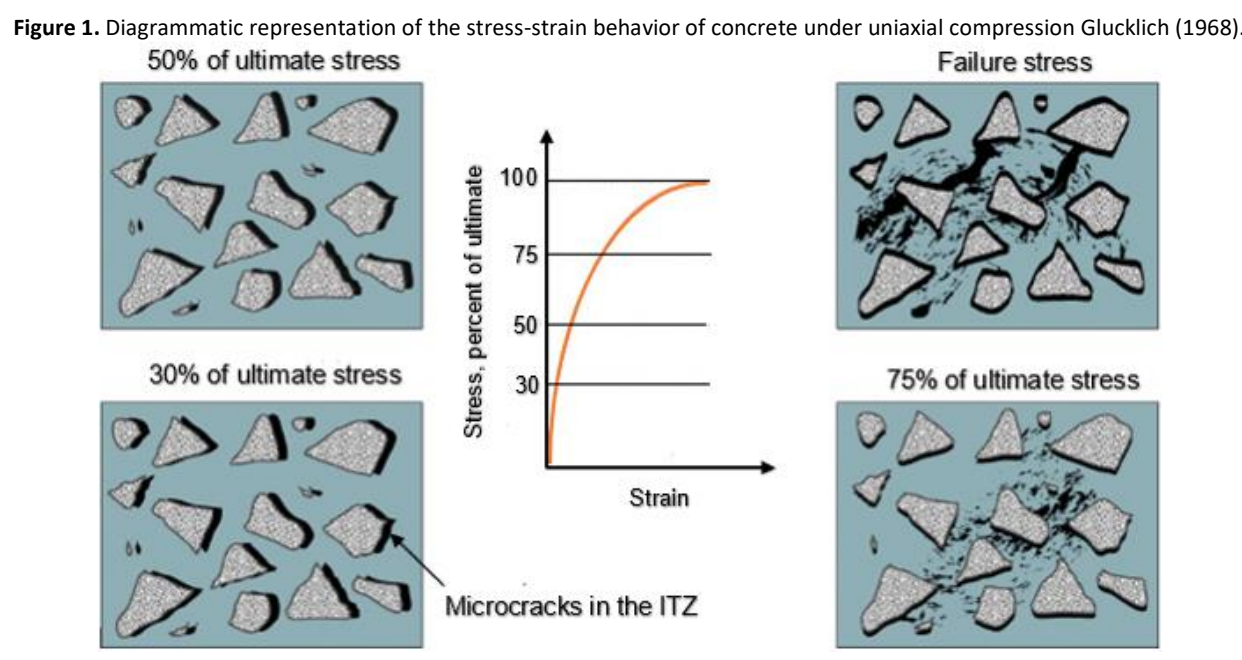

Various techniques have been used in the last 50 years to detect and examine cracks in concrete. The optical microscope method is a low-cost, practical, and common method for this purpose (Ollivier, 1985). Performed the first optical microscope study on thin concrete sections from axially loaded concrete cylinders. With the microscope and image processing method, they detected cracks on the aggregate-cement-paste interface (Nemati et al., 1998). Knab et al. (1984) examined the refraction points in the mortar also with an optical microscope and image processing technique. Litorowicz (2006), Glinicki \& Litorowicz (2006) have applied an optical microscope and image processing method to examine the development of crack patterns in durability-induced deformations. Shuguang et al. (2013) quantitatively determined microcracking properties using an optical microscope method in epoxy-impregnated concretes that had various degrees of alkali-aggregate reaction (AAR). Visualization of crack development caused by different mechanical deformations through image analysis is essential for failure analysis and improved design (Alterman, Akita, Neitzert, 2011).

\section{Description of the problem}

Explaining the deforming behavior of concrete in terms of material size and examining the behavior and deformations of the components that make up the concrete against the load can provide important information in revealing the carrier feature of the concrete.

State of the art

In this study, deformations occurring in concrete under different load effects were investigated using the image processing technique. Thin section samples were removed from concrete experimental samples, and the deformations 
observed in the microscope examination were analyzed by the image processing technique resulting in quantitative data (e.g., crack length and width)

Methodology

\section{Material}

Concrete mixtures were prepared in accordance with the TS EN 206-1 (2014) standard using fine aggregate in the range of 0-4 mm and coarse aggregate in the range of 4-12 mm and 12-22 mm (Table 1). Portland cement CEM I $42.5 \mathrm{R}$ compliant with the TS EN 197-1 (2012) standard was used as a binder. Concrete samples were shaped in $15 \mathrm{~cm}$ edged cubes, and standard curing was applied in the curing pool at $23 \pm 2{ }^{\circ} \mathrm{C}$ for 28 days. Thirteen concrete experimental samples were prepared for mechanical and microstructural investigations.

Table 1. Mix design parameters for $1 \mathrm{~m}^{3}$. (Self-Elaboration).

\begin{tabular}{cc}
\hline Concrete Component & Amount $(\mathrm{kg})$ \\
\hline Fine aggregate $(0-4 \mathrm{~mm})$ & 1067 \\
Coarse aggregate $(4-12 \mathrm{~mm})$ & 637 \\
Coarse aggregate $(12-22 \mathrm{~mm})$ & 338 \\
Cement & 280 \\
Water & 137 \\
Superplasticizer & 3.22 \\
\hline
\end{tabular}

\section{Methods}

Elastic and plastic boundaries of concrete test samples were determined according to the secant method. The stress value corresponding to $40 \%$ of the maximum tensile value for the elastic boundary and the tensile value corresponding to $60 \%$ of the maximum tensile value for the plastic boundary were taken as references (Erdoğan, 2010; Neville, 1981). After the strength and stress deformation values on the deformation-controlled press for three of the concrete samples were obtained according to the TS EN 12390-3 (2010) standard, the ultrasonic pulse velocity time of the concrete was determined in accordance with ASTM C597-09 (2009).

To examine the deformations occurring in the microstructure, the samples, which were subjected to the determined loads, were then treated with epoxy to re-consolidate the thin sections that will be examined on the microstructure level (Figure 2). The epoxy-coated samples were cut from the middle, where the loading direction originated, and divided into four regions. Thin-section samples, $7.5 \mathrm{~cm} \times 7.5 \mathrm{~cm} \times 3 \mathrm{~mm}$, were taken from each separated region (Figure 3). Thin-section examinations were performed with an Olympus SZX7 stereomicroscope at $1 X$ magnification and photographed. The photographs were analyzed using image processing technique (Figure 4).

Figure 2. Mixing process: a) produce of sample, b, and c) epoxy cover, d) preparation of epoxy concrete samples, and e) cutting epoxy concrete samples with a head

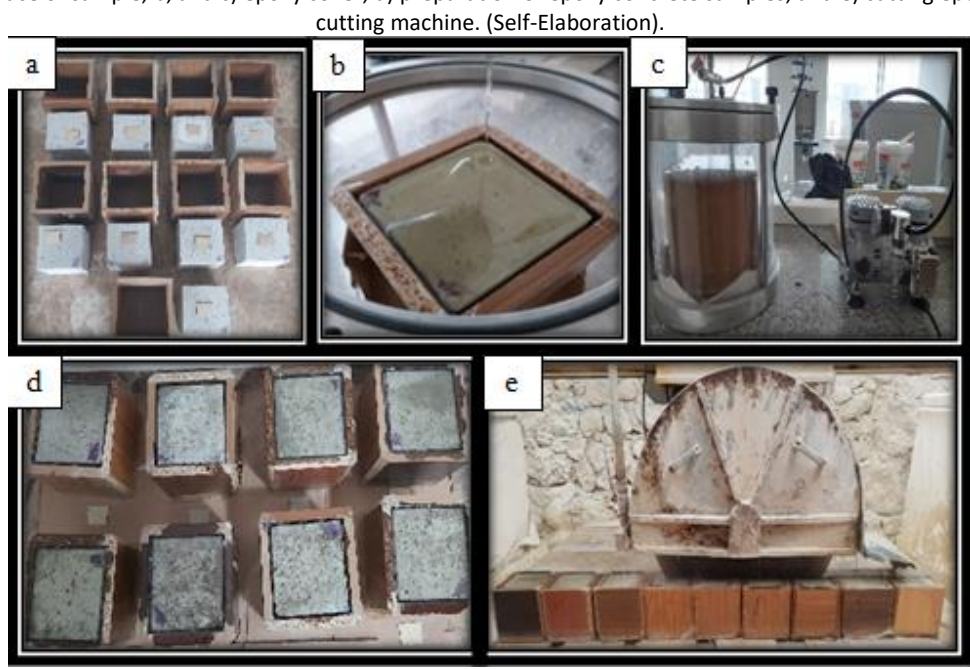


Figure 3. Separation of concrete samples into regions and extraction of thin sections. (Self-Elaboration).

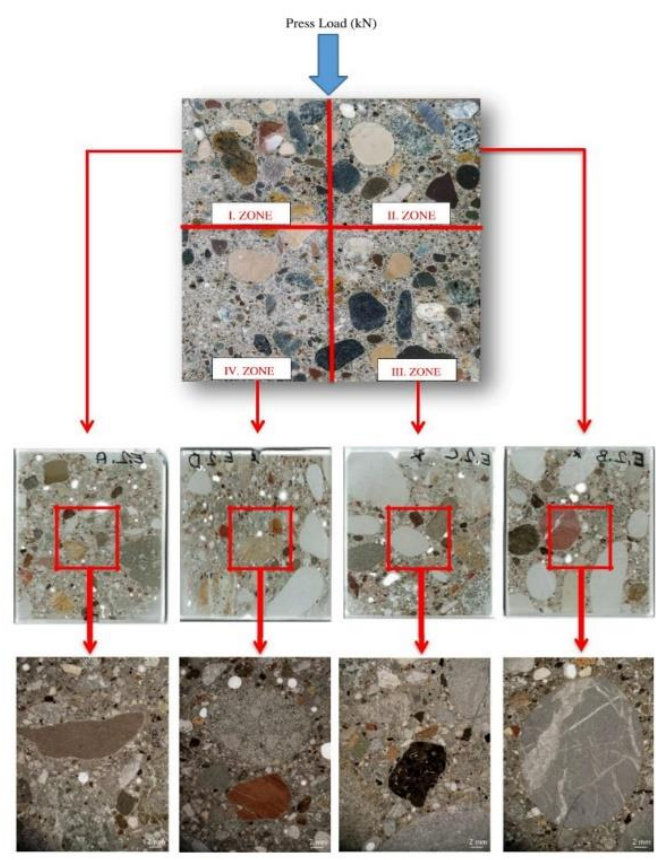

Figure 4. Image analysis of crack formation in concrete samples.

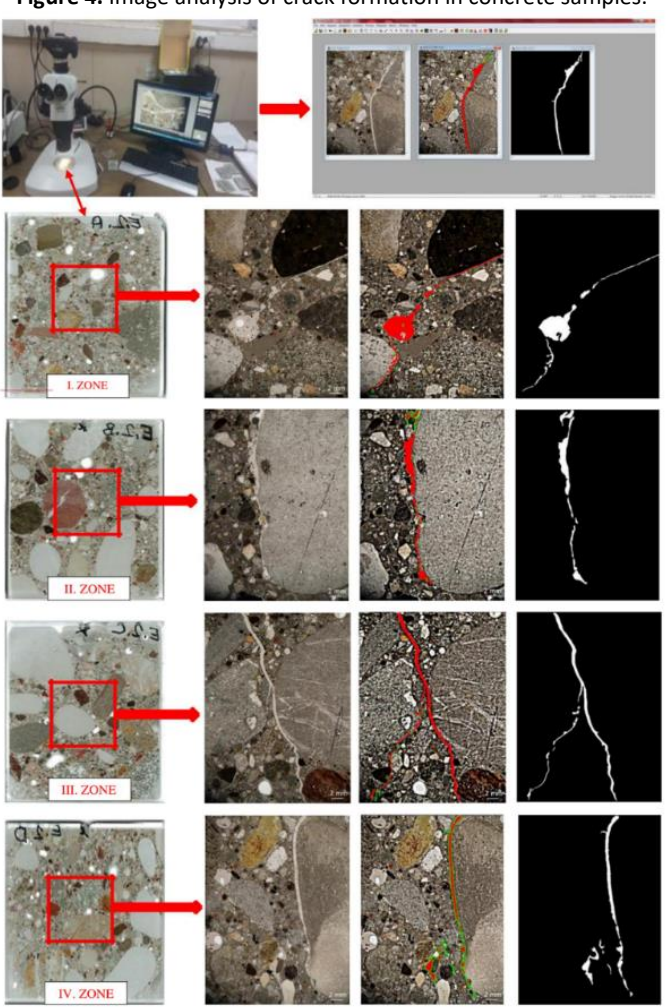

\section{Compressive strength findings}

The stress-strain curves and the average stress-strain curve obtained from a deformation-controlled press device on three 15-cm-edged cube samples are shown in Figure 5. Based on the average stress-strain curve, the corresponding values for the ten concrete samples are given in Table 2. For P.4 concrete, the press device was unloaded as soon as the prescribed load was reached because failure occurred. 
Figure 5. Three cube concrete sample stress-strain curves and the average stress-strain curve and a representation of mean stress-strain values. (Self-Elaboration).
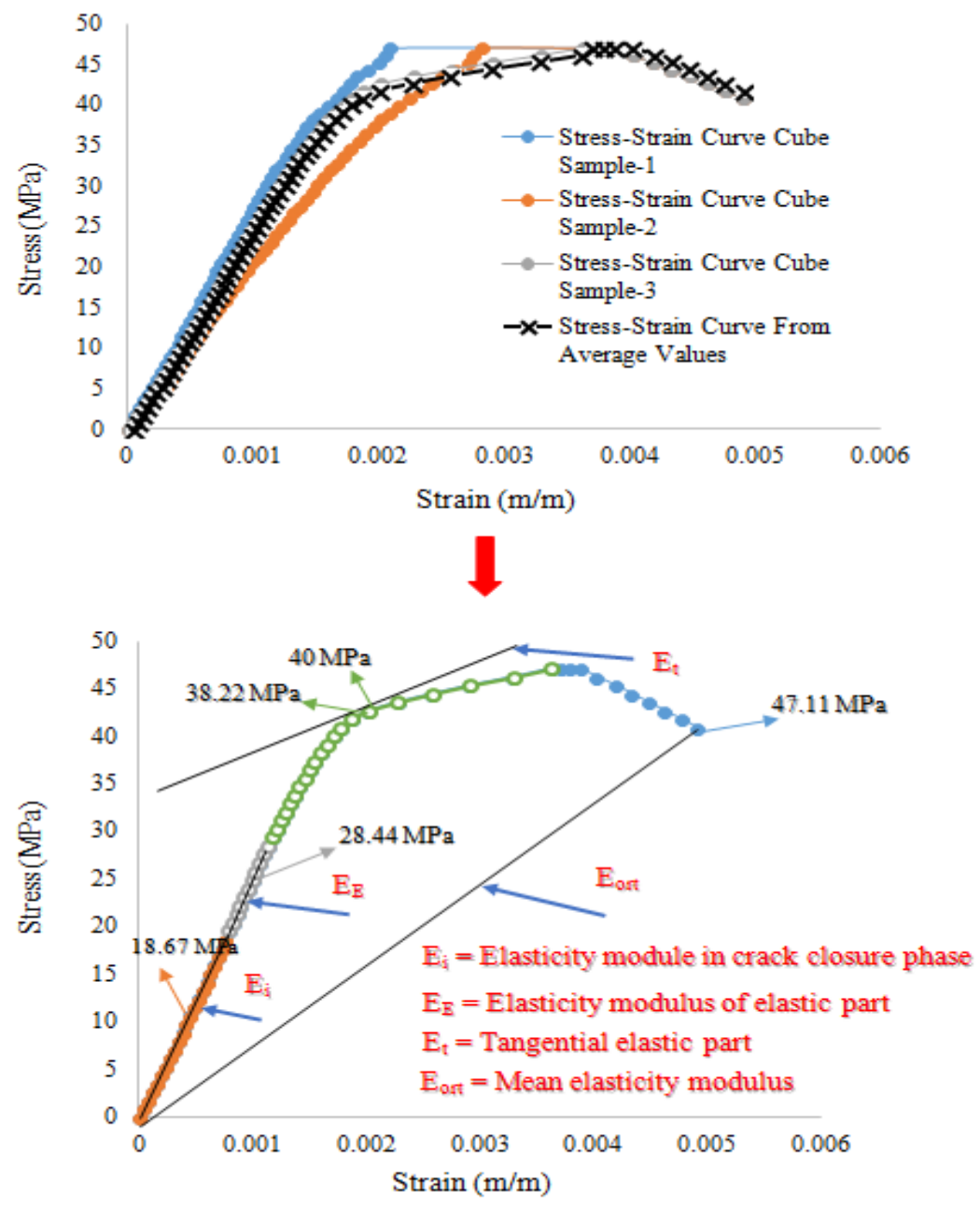

Table 2. Numerical findings of the experiment series. (Self-Elaboration).

$\begin{array}{ccccc}\begin{array}{c}\text { Experiment series } \\ \text { name }\end{array} & \text { Stress } & \text { Strain }(\mathrm{m} / \mathrm{m}) & \text { Maximum stress } & \text { Waiting times under } \\ (\mathrm{MPa}) & \text { load }(\mathrm{h})\end{array}$

\begin{tabular}{lcccc}
\hline E.1-E.2 & 18.67 & 0.000758 & 40 & 2 \\
P.1-P.2 & 28.44 & 0.001135 & 60 & 2 \\
P.3 & 40.00 & 0.001708 & 85 & 2 \\
P.4 & 38.22 & 0.001592 & 81 & 2 \\
P.5-P.6 & 40.00 & 0.001708 & 85 & - \\
K.1-K.2 & 47.11 & 0.003621 & 100 & - \\
\hline
\end{tabular}

$\mathrm{E}=$ Elastic Zone, $\mathrm{P}=$ Plastic Zone, $\mathrm{K}=$ Fracture Zone 


\section{Ultrasonic pulse velocity}

The ultrasound pulse velocity findings are given in Table 3. The high bulk density concrete samples experienced high ultrasonic pulse velocities, and the average ultrasonic pulse velocity $(\mathrm{Vp}=4.99>4.55 \mathrm{~km} / \mathrm{s})$ is found to be "very good" concrete quality (Whitehurst, 1951).

\begin{tabular}{|c|c|c|c|c|}
\hline & $\begin{array}{c}\text { Average } \\
\text { bulk density } \\
\left(\mathrm{kg} / \mathrm{m}^{3}\right)\end{array}$ & $\begin{array}{c}\text { Standard } \\
\text { deviation } \\
\left(\mathrm{kg} / \mathrm{m}^{3}\right)\end{array}$ & $\begin{array}{l}\text { Average } \\
\qquad V p \\
(\mathrm{~km} / \mathrm{s})\end{array}$ & $\begin{array}{c}\text { Standard } \\
\text { deviation } \\
(\mathrm{km} / \mathrm{s})\end{array}$ \\
\hline $\begin{array}{l}\text { Experiment } \\
\text { series }\end{array}$ & 2471 & \pm 14 & 4.99 & \pm 0.12 \\
\hline
\end{tabular}

\section{Microstructure findings}

Thin sections of concrete samples were examined under an optical microscope. Deformation measurements were taken of the prominent cracks detected as a result of the investigations.

\section{Elastic zone findings}

Under a load of $40 \%$ of the maximum stress for two hours, concrete samples taken from four regions were examined in thin sections. Each section exhibited stability preserved by the coarse aggregate with no evidence of cracking. The dough areas remained cohesive. See Figure 6.

The literature states that significant cracks in the concrete material in the elastic region do not occur in the cement pulp (Mindess \& Young, 1986). In their study, Lilliu \& van Mier (2007) found that there were no significant cracks in the concrete material at $35 \%$ of the maximum stress. In research by Malek et al. (2017), cracks in the concrete material were not evident in the elastic region. These findings in the literature are similar to the data obtained in the elastic region of the samples tested.

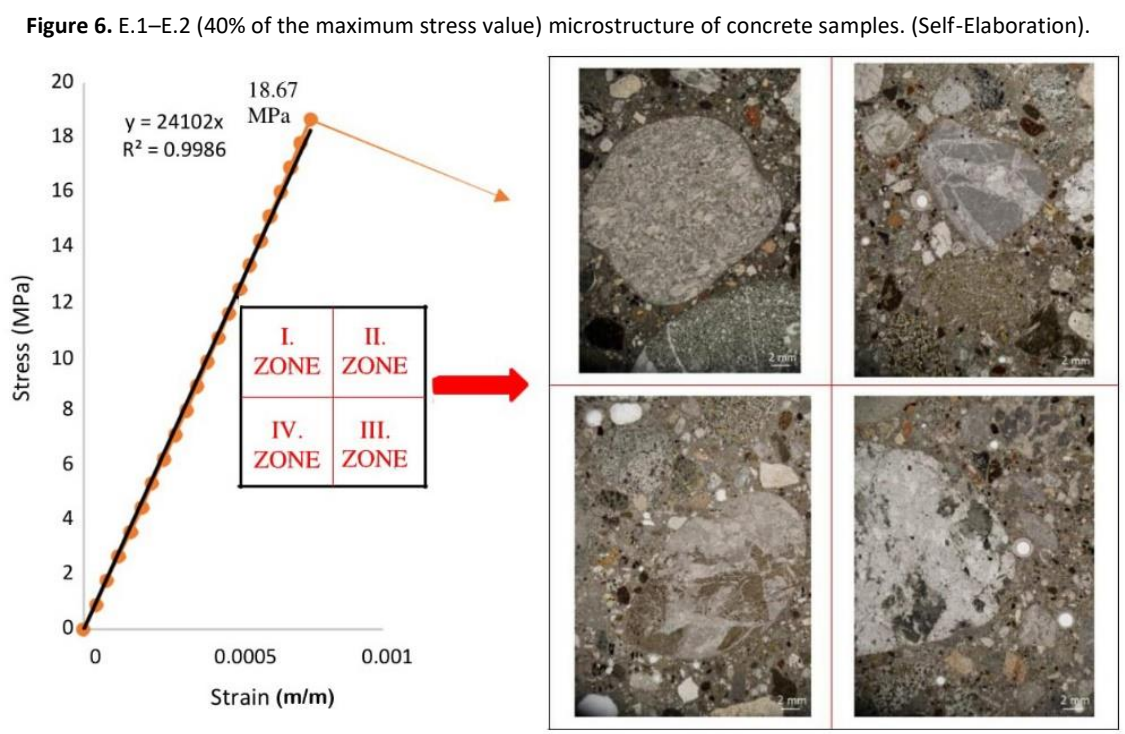

\section{Plastic zone findings}

In the plastic region, it is expected that many negligible microcracks may form on the aggregate-cement-paste interface and that concrete samples will begin to deviate towards the non-linearity in the stress-deceleration curve.

Under a load of $60 \%$ of the maximum stress for two hours, concrete samples taken from four regions were examined in thin sections. Each section exhibited stable elastic behavior due to the aggregate-cement-paste interface with no evidence of cracking. The dough areas remained cohesive. See Figure 7. 
The literature states that significant cracks in concrete material in the plastic region do not occur in the cement paste (Bache \& Christensen, 1965; Meyers, 1968). In their study, Lilliu \& van Mier (2007) found that cracks in the decking surface of aggregate-cement pulp in the concrete material in the plastic region were negligible. A study by Zhang et al. (2007) revealed that no significant cracks occur in the concrete material up to $67 \%$ of the maximum stress. In research by Malek et al. (2017), there were no significant cracks in the concrete material up to $70 \%$ of the maximum stress. These findings in the literature are similar to the current project data obtained in the elastic region.

The microstructure of the concrete experiment sample that was loaded for two hours under $85 \%$ of the maximum stress is notably different from the load structure of $60 \%$ (Figure 8). Significant, deep cracks were detected. At this point, the unit deformations occurring in the concrete increase faster than the strain formed. Prominent crack analysis data are given in Table 4.

Figure 7. P.1-P.2 microstructure of concrete samples (60\% of the maximum stress value). (Self-Elaboration)
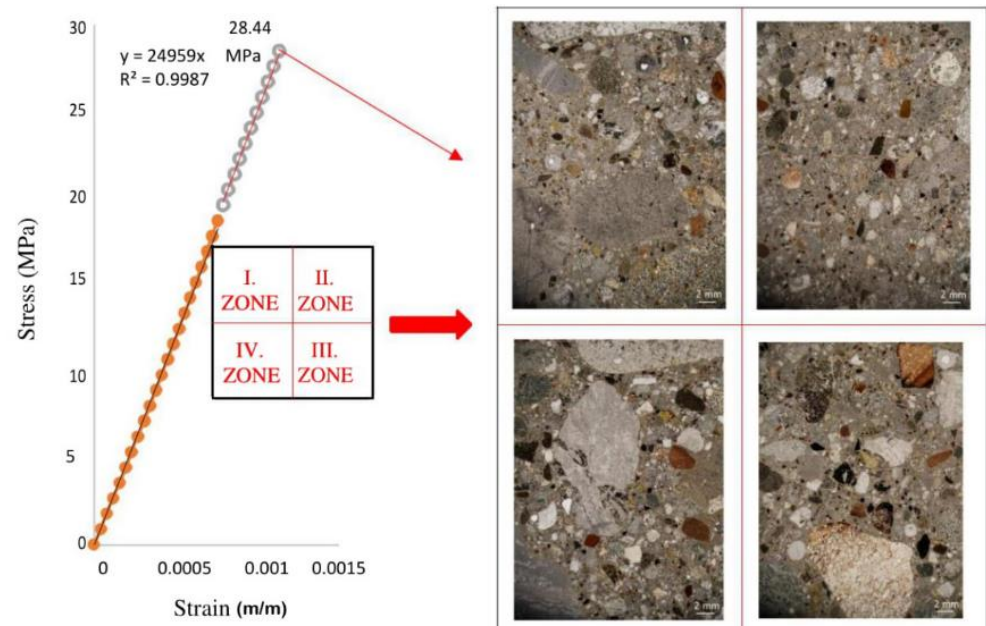

Table 4. P.3 analysis data of prominent cracks of the concrete sample. (Self-Elaboration).

\begin{tabular}{cccc}
\hline Zone & Crack dimensions & Length $(\mathrm{mm})$ & Width $(\mathrm{mm})$ \\
\hline \multirow{2}{*}{ I } & Maximum & 18.328 & 3.054 \\
& Minimum & 0.665 & 0.223 \\
& Average & 4.968 & 1.188 \\
\hline \multirow{2}{*}{ II } & Maximum & 29.505 & 4.128 \\
& Minimum & 29.505 & 4.128 \\
& Average & 29.505 & 4.128 \\
\hline \multirow{2}{*}{ III } & Maximum & 15.128 & 2.849 \\
& Minimum & 0.765 & 0.180 \\
& Average & 2.759 & 1.066 \\
\hline
\end{tabular}

In relevant studies, at $85 \%$ of the maximum stress in concrete, significant cracks in the cement paste appeared parallel to the loading direction and spread irregularly (Bache \& Christensen, 1965; Johnston, 1970b; Meyers, 1968; Tanigawa \& Yamada, 1978). Lilliu \& van Mier (2007) found that deep cracks occur in cement pulp at $81 \%$ of the maximum stress. These findings in the literature support data obtained at $85 \%$ of the maximum stress in this project. Moreover, in the methodology of the P. 3 concrete sample, the cracks in the coarse aggregate are given in Figure 9. 
Figure 8. P. 3 concrete sample at $85 \%$ of the maximum stress: a) microstructure image, b) processed microstructure image, and c) crack measurement. (Self-Elaboration).
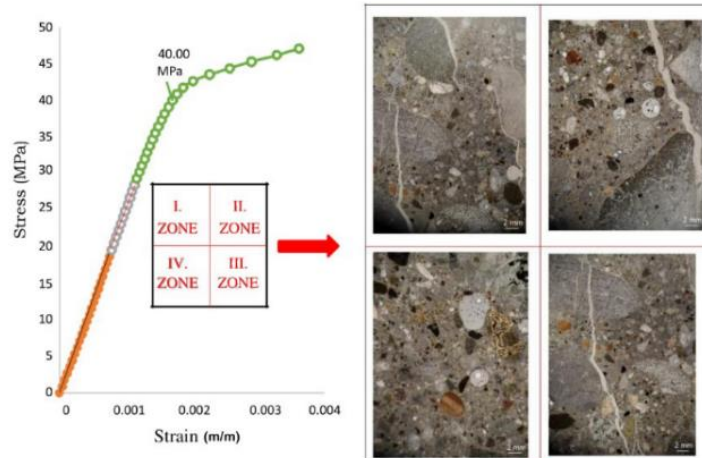

(a)
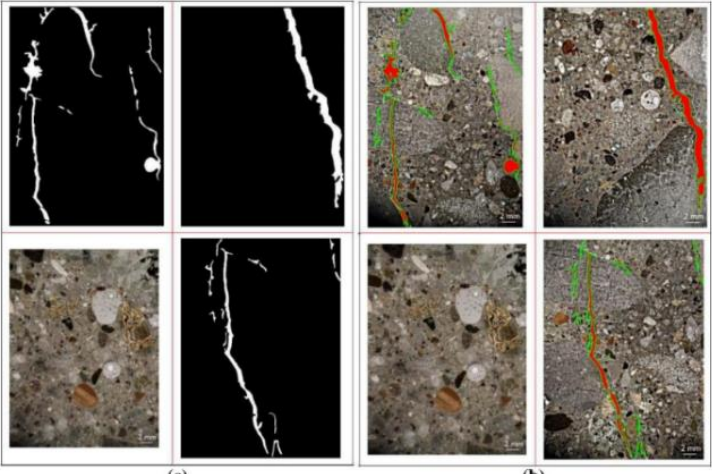

Figure 9. P. 3 concrete sample at $85 \%$ of the maximum stress: a) microstructure image, b) processed microstructure image, and c) crack measurement. (Self-Elaboration).

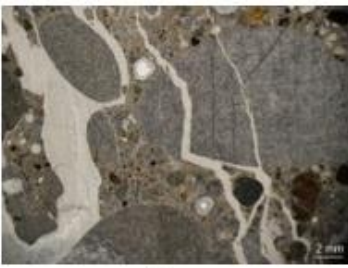

(a)

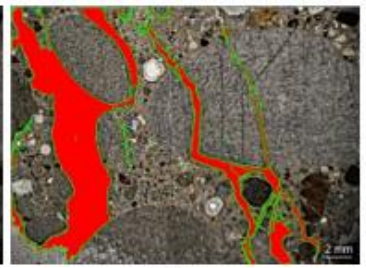

(b)

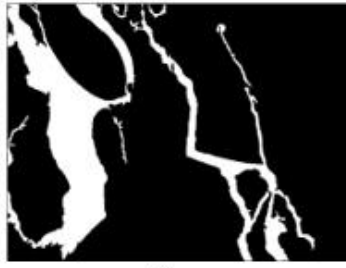

(c)

\section{Fracture zone findings}

Significant, deep cracks were detected in the fracture zone (Figure 10). Prominent crack analysis data are given in Table 5.

Table 5. K.1-K.2 analysis data of prominent cracks of concrete samples. (Self-Elaboration).

\begin{tabular}{cccc}
\hline Zone & Crack dimensions & Length $(\mathrm{mm})$ & Width $(\mathrm{mm})$ \\
\hline \multirow{2}{*}{ I } & Maximum & 18.050 & 2.906 \\
& Minimum & 0.485 & 0.231 \\
& Average & 4.389 & 0.982 \\
\hline \multirow{2}{*}{ II } & Maximum & 32.688 & 2.331 \\
& Minimum & 0.305 & 0.106 \\
& Average & 4.497 & 0.583 \\
\hline
\end{tabular}


Figure 10. K.1-K.2 concrete sample in the fracture zone: a) microstructure image, b) processed microstructure image, and c) crack measurement image. (SelfElaboration).
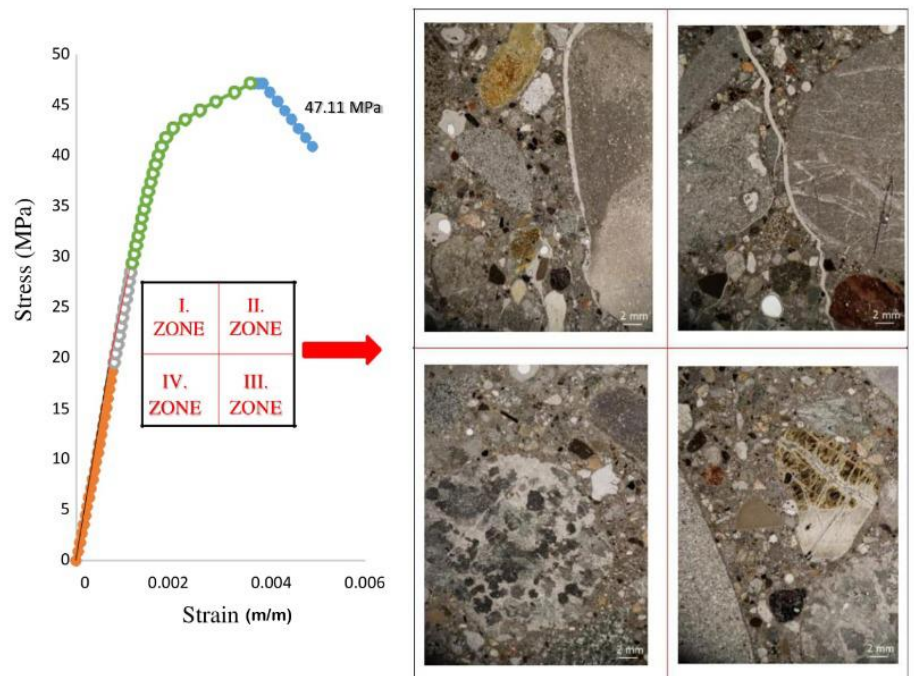

(a)
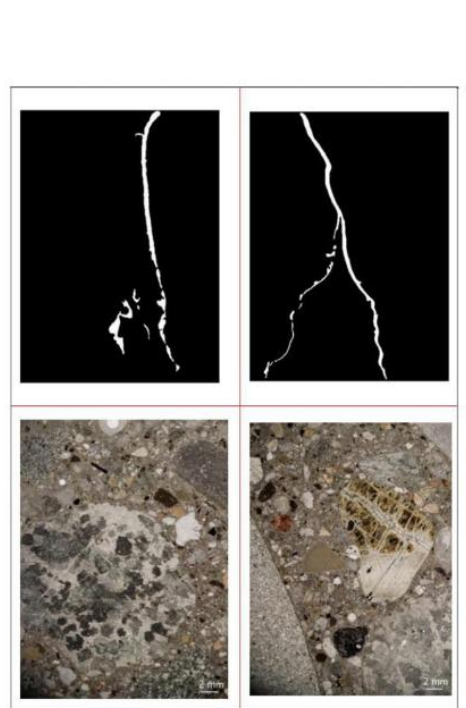

(c)

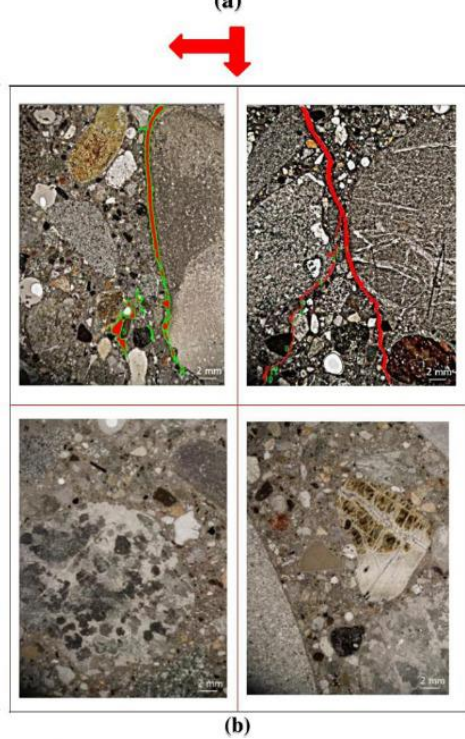

\section{Evaluation of the relationship between the stress-strain curve and data analysis of the prominent cracks}

The relationship between P.3 and K.1-K.2 stress-strain values and the analysis data of prominent cracks is described below:

- As the stress and strain of the concrete samples increase, the average length of the prominent cracks also increases (Figure 11). The correlation R-squared value between stress and average crack length in the concrete samples is $R^{2}=1$, as is the correlation value between strain and average crack length. High $R^{2}$ values (i.e., $R^{2} \approx 1$ ) indicate a strong relationship between the crack height elongation and stress-strain values. 
Figure 11. Relationship between stress-strain and average crack length of concrete samples. (Self-Elaboration).

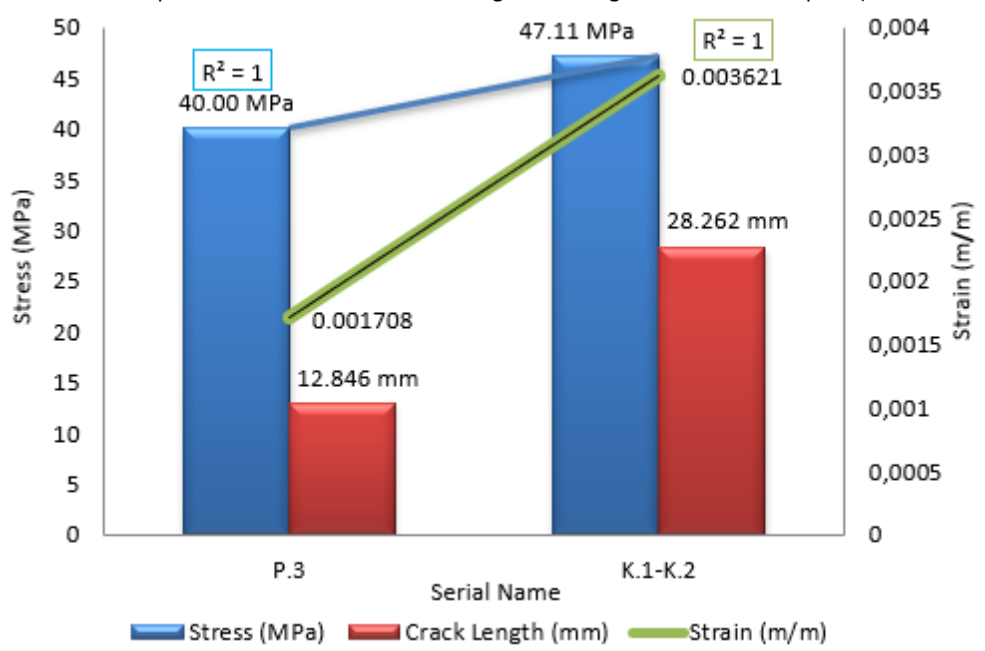

Figure 12. Relationship between stress-strain and average crack width of concrete samples. (Self-Elaboration).

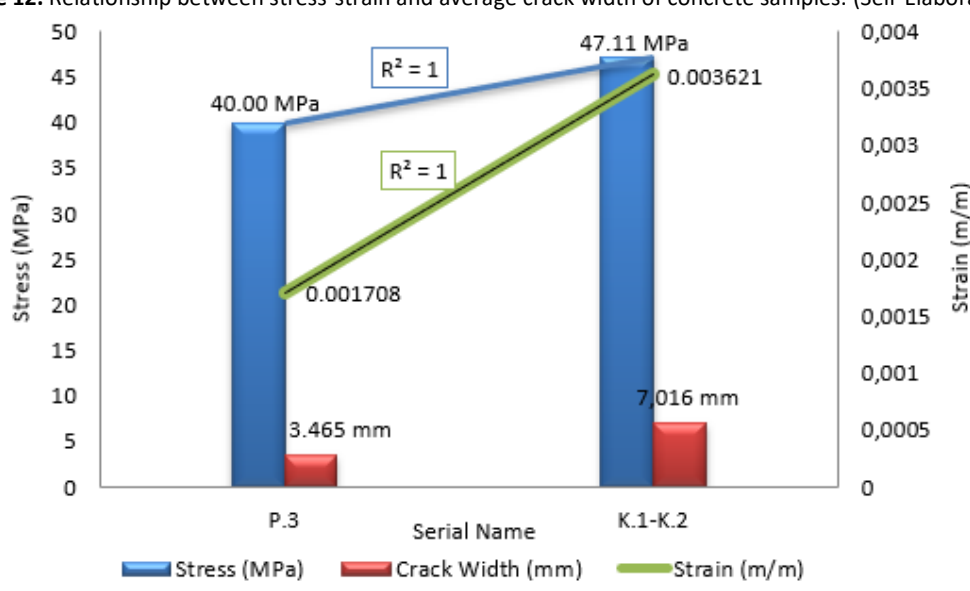

- The average crack width increases as the stress and strain values of the concrete samples increase (Figure 12). The correlation R-squared value between stress and average crack width of the concrete samples is $R 2=1$, as is the correlation value between strain and average crack width. High R2 values (i.e., R2 $\approx 1$ ) indicate a strong relationship between the crack width and stress-strain values.

In his study, Glucklich (1968) found that no significant cracks occurred in concrete material up to $30 \%$ and $50 \%$ of the maximum stress. However, deep cracks occurred in the cement paste at $75 \%$ of the maximum stress. Unlike the literature, the current study showed no significant cracks in the concrete material up to $40 \%$ and $60 \%$ of the maximum stress, and deep cracks occurred in the cement paste at $85 \%$ of the maximum stress. The relationship between the stress-strain curve and the apparent cracks is shown in Figure 13. 
Figure 13. Diagrammatic representation of the stress-strain behavior of concrete under uniaxial compression. (Self-Elaboration).

(1) $40 \%$ of ultimate stress

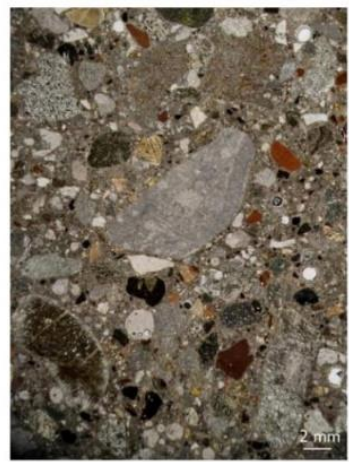

(2) $60 \%$ of ultimate stress

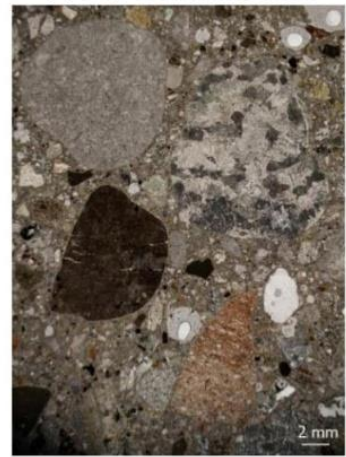

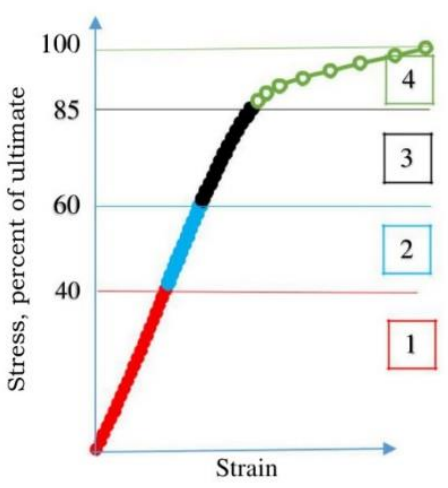

(3) $85 \%$ of ultimate stress

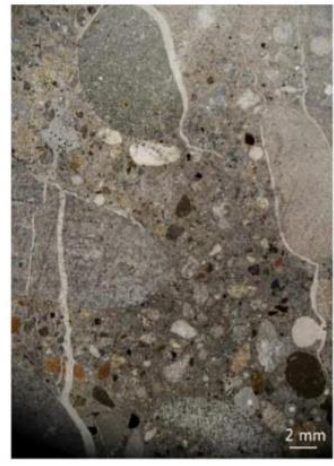

(4) Failure stress

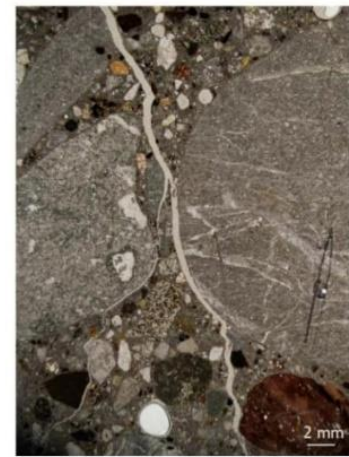

The following results were obtained from the study:

- The average ultrasound pulse velocity of concrete samples was $4.99 \pm 0.12 \mathrm{~km} / \mathrm{s}$.

- Stress values of concrete samples held under loading were determined to be $18.76 \mathrm{MPa}$ for E.1-E.2, 28.44 MPa for P.1-P.2, 40 MPa for P.3, 38.22 MPa for P.4, 40 MPa for P.5-P.6, and 47.11 MPa for K.1-K.2.

- Cracks will be parallel to the compressive loading at the aggregate-cement-paste interface. It has been determined that the cement paste has spread into it.

- As the strain values of concrete samples increase, the lengths and widths of the formed cracks increase. It is understood that deformation can break concrete samples.

- There were no apparent cracks in the internal structure of concrete samples in the elastic region, which is up to $40 \%$ of the maximum stress value.

- There are no obvious cracks in the internal structure of concrete in the plastic region, which is at $60 \%$ of the maximum stress value.

- Significant cracks occur in the internal structure of concrete at $85 \%$ of the maximum stress value. At $85 \%$ of the ultimate stress, crack length was measured as 0.665-29.505 mm and crack width 0.180-4.128 mm.

- The critical stress value must reach $85 \%$ of the maximum stress for cracks to appear in the concrete's internal structure. 
In particular, these methods are recommended for future experimental studies when evaluating crack formation in concrete with nano-additives for strengthening the cement-aggregate interface.

References

ASTM C597-09. (2009). Standard Test Method for Pulse Velocity Through Concrete, USA.

Bazant, Z. P., \& Hubler, M. H. (2014). Theory of cyclic creep of concrete based on Paris law for fatigue growth of subcritical microcracks. Journal of the Mechanics and Physics of Solids, 63(1), 187-200. https://doi.org/10.1016/j.jmps.2013.09.010.

Bentz, D. P. (2006). Influence of shrinkage-reducing admixtures on early-age properties of cement pastes. Journal of Advanced Concrete Technology, 4(3), 423-429. https://doi.org/10.3151/jact.4.423.

Castro, M., \& Sánchez, J. A. (2008). Estimation of asphalt concrete fatigue curves - A damage theory approach. Construction and Building Materials, 22(6), 1232-1238. https://doi.org/10.1016/j.conbuildmat.2007.01.012.

Alterman D., Akita H., Neitzert T., \& J. A. (2011). An impregnation technique for crack identification following uniaxial tension tests. Adv. Mater. Res., 275, 51-54.

Erdem, S., Gürbüz, E., \& Uysal, M. (2018). Micro-mechanical analysis and X-ray computed tomography quantification of damage in concrete with industrial by-products and construction waste. Journal of Cleaner Production, 189, 933-940, https://doi.org/10.1016/j.jclepro.2018.04.089.

Erdoğan, T. Y. (2010). Concrete (5th editio). METU publishing.

Glinicki, M. A., \& Litorowicz, A. (2006). Crack system evaluation in concrete elements at mesoscale. Bulletin of the Polish Academy of Sciences: Technical Sciences, 54(4), 371-379.

Golewski, G. L. (2018). Evaluation of morphology and size of cracks of the Interfacial Transition Zone (ITZ) in concrete containing fly ash (FA). https://doi.org/10.1016/j.jhazmat.2018.06.016.

Bache, H.H., \& Christensen P.N. (1965). Observations on strength and fracture in lightweight and ordinary concrete. Proceedings of and Internatiol Conference on the Structure of Concrete and Its Behaviour under Load.

Glucklich, J. (1968). Proceedings of International Conference on the Structure of Concrete. 176-185.

Li, J., Wu, J. Y., \& Chen, J. B. (2014). Stochastic Damage Mechanics of Concrete Structures. In Stochastic Damage Mechanics of Concrete Structures (pp. 1-9). Science Press.

Ollivier, J.P. (1985). A nondestructive procedure to observe the microcracks of concrete by scanning electron microscopy. Cem Concr Res, 15, 10551060.

Johnston, C. D. (1970a). Strength and deformation of concrete in uniaxial tension and compression. Magazine of Concrete Research, 22(70), 5-16.

Johnston, C. D. (1970b). Strength and deformation of concrete in uniaxial tension and compression. Magazine of Concrete Research, 22(70), 5-16. https://doi.org/10.1680/macr.1970.22.70.5.

Jones, R., \& Gatfield, E. N. (1955). Testing Concrete by on Ultrasonic Pulse Technique (p. 34). DISR Road Research, Tech.

Knab, L. I., Walker, H. N., Clifton, J. R., \& Fuller, E. R. (1984). Fluorescent thin sections to observe the fracture zone in mortar. Cement and Concrete Research, 14(3), 339-344. https://doi.org/10.1016/0008-8846(84)90051-6.

Kong, X., Fang, Q., \& Hong, J. (2019). A new damage-based nonlocal model for dynamic tensile failure of concrete material. International Journal of Impact Engineering, 132, 103336. https://doi.org/10.1016/j.ijimpeng.2019.103336.

Lang, L., Zhu, Z., Zhang, X., Qiu, H., \& zhou, C. (2019). Investigation of crack dynamic parameters and crack arresting technique in concrete under impacts. Construction and Building Materials, 199, 321-334. https://doi.org/10.1016/j.conbuildmat.2018.12.029.

Shuguang, L., Yihui, L., \& Gaixin, C. (2013). Quantitative damage evaluation of AAR-affected concrete by DIP technique. Magazine of Concrete Research, 65(5), 332-342.

Lilliu, G., \& van Mier, J. G. M. (2007). On the relative use of micro-mechanical lattice analysis of 3-phase particle composites. Engineering Fracture Mechanics, 74(7), 1174-1189, https://doi.org/10.1016/j.engfracmech.2006.12.018.

Litorowicz, A. (2006). Identification and quantification of cracks in concrete by optical fluorescent microscopy. Cement and Concrete Research, 36(8), 1508-1515. https://doi.org/10.1016/j.cemconres.2006.05.011.

Malek, A., Scott, A., Pampanin, S., \& MacRae, G. (2017). Post-event damage assessment of concrete using the fluorescent microscopy technique. Cement and Concrete Research, 102, 203-211. https://doi.org/10.1016/j.cemconres.2017.09.015.

Mahfuz, P. \& Illker, T. (2021). Microstructural investigation and strength properties of structural lightweight concrete produced with zeolitic tuff aggregate. Journal of Building Engineering, 43, 2352-7102. https://doi.org/10.1016/j.jobe.2021.102863.

Mehta, P. K., \& Monteiro, P. J. M. (2006). Concrete: Microstructure, Properties, and Materials. McGraw-Hill Companies.

Mehta, P. K. (2006). Concrete: structure, properties and materials.

Meyers, O. F. S. (1968). Deformation of plain concrete. Paper for the Fifth International Symposium on the Chemistry of Cement. 
Alembagheri, M., \& Ghaemian, M. (2013). Seismic assessment of concrete gravity dams using capacity estimation and damage indexes. Earthquake Engineering \& Structural Dynamics, 42, 123-144. https://doi.org/10.1002/eqe

Nemati, K. M., Monteiro, P. J. M., \& Scrivener, K. L. (1998). Analysis of compressive stress-induced cracks in concrete. ACl Materials Journal, 95(5), 617-630. https://doi.org/10.14359/404.

Neville, A.M. (1981). Properties of concrete. Pitman Books Limited.

Profant, T., Hrstka, M., \& Klusák, J. (2019). An asymptotic analysis of crack initiation from an interfacial zone surrounding the circular inclusion. Composite Structures, 208, 479-497. https://doi.org/10.1016/j.compstruct.2018.10.020.

Mindess, S., \& Young, J. F. (1986). Concrete. Prentice-Hall.

Santiago, S. D., \& Hilsdorf, H. K. (1973). Fracture mechanisms of concrete under compressive loads. Cement and Concrete Research, 3(4), 363-388. https://doi.org/10.1016/0008-8846(73)90076-8.

Shen, W., Li, X., Gan, G., Cao, L., Li, C., \& Bai, J. (2016). Experimental investigation on shrinkage and water desorption of the paste in high performance concrete. Construction and Building Materials, 114, 618-624. https://doi.org/10.1016/j.conbuildmat.2016.03.183.

Tanigawa, L., \& Yamadaka, K. (1978). Size Effect in Compressive Strength of Concrete. Cement and Concrete Research, 8(2), 181-190. https://doi.org/10.1016/0008-8846(78)90007-8.

TS EN 12390-3: 2010, Concrete- Hardened concrete tests- Part 3: Estimation of compressive strength in test samples, Turkey.

TS EN 197-1: 2012, Cement - Part 1: General Cements - Composition, Properties and Eligibility Criteria. Concrete properties, performance, manufacturing, and compliance, Turkey.

Upadhyaya, Y. S., \& Sridhara, B. K. (2012). Fatigue life prediction: A Continuum Damage Mechanics and Fracture Mechanics approach. Materials and Design, 35, 220-224. https://doi.org/10.1016/j.matdes.2011.09.049.

Whitehurst, E. A. (1951). Soniscope Tests Concrete Structures. ACI Journal Proceedings, 47(2), 433-444. https://doi.org/10.14359/12004.

Xue, Y., Dang, F., Liu, F., Li, R., Ranjith, P. G., Wang, S., Cao, Z., \& Yang, Y. (2018). An elastoplastic model for gas flow characteristics around drainage borehole considering post-peak failure and elastic compaction. Environmental Earth Sciences, 77(19), 1-18. https://doi.org/10.1007/s12665018-7855-y.

Yang, C., \& Chen, J. (2019). Fully noncontact nonlinear ultrasonic characterization of thermal damage in concrete and correlation with microscopic evidence of material cracking. Cement and Concrete Research, 123, 105797. https://doi.org/10.1016/j.cemconres.2019.105797.

Zaitsev, J. W., \& Wittmann, F. H. (1973). Fracture of porous viscoelastic materials under multiaxial state of stress. Cement and Concrete Research, 3(4), 389-395. https://doi.org/10.1016/0008-8846(73)90077-X.

Zhang, X., Xu, S., \& Zheng, S. (2007). Experimental measurement of double-K fracture parameters of concrete with small-size aggregates. Frontiers of Architecture and Civil Engineering in China, 1(4), 448-457. https://doi.org/10.1007/s11709-007-0061-8. 